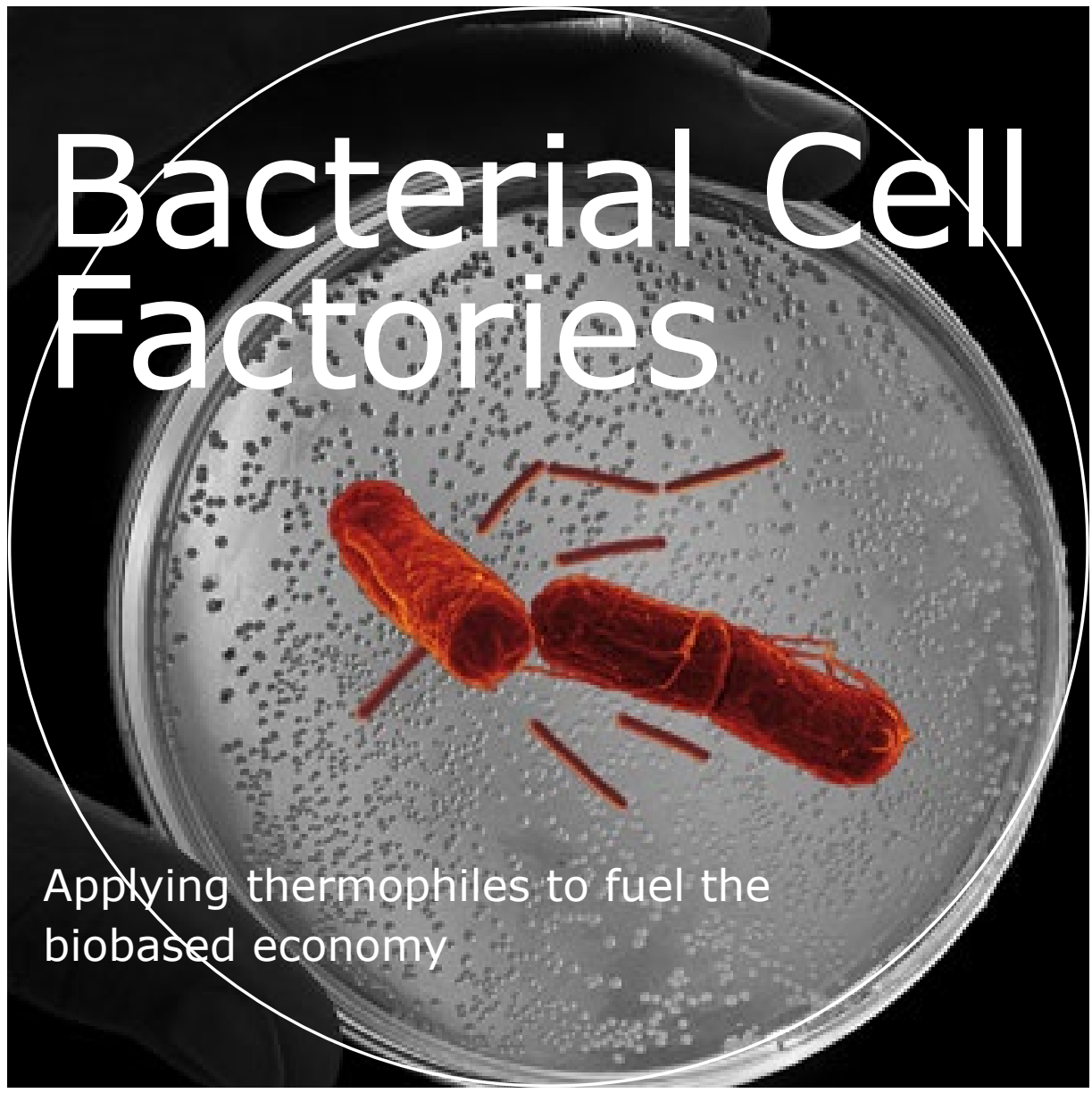

Prof.dr Richard van Kranenburg

Inaugural lecture upon taking up the position of Special Professor of Bacterial Cell Factories at Wageningen University \& Research on 23 March 2017 


\section{Bacterial Cell Factories}

Applying thermophiles to fuel the biobased economy

\section{Prof.dr Richard van Kranenburg}

Inaugural lecture upon taking up the position of Special Professor of Bacterial Cell Factories at Wageningen University \& Research on 23 March 2017 
DOI $10.18174 / 412409$

ISBN 978-94-6343-175-O 


\section{Bacterial Cell Factories \\ Applying thermophiles to fuel the biobased economy}

Esteemed Rector Magnificus, dear colleagues, family and friends. A warm welcome to all of you.

In this inaugural lecture I will introduce you to the fascinating world of bacterial cell factories and explain their relevance for the biobased economy.

Bacteria are single-cellular organisms. There are many different species that all have their own characteristics. Some can be used in industrial applications. Like factories, bacteria can convert feedstocks into useful products. Therefore, we can consider them as tiny factories on their own, or bacterial cell factories.
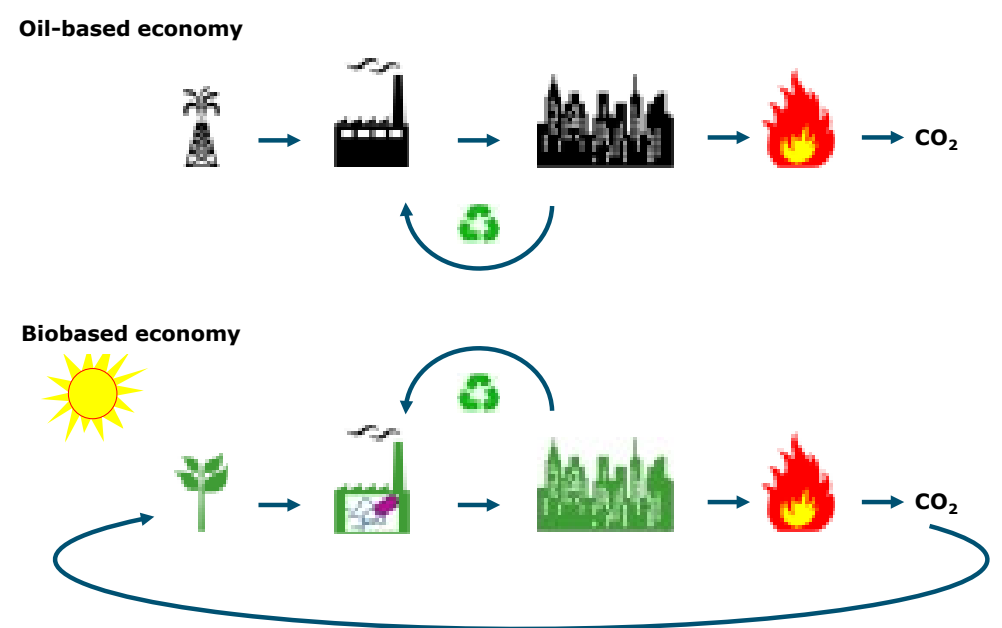

Figure 1. Biobased versus Oil-based economy 


\section{Bacterial cell factories and the biobased economy}

Another term that needs introduction is the biobased economy. This refers to all economic activity based on raw materials of biological origin. Since the middle of the $2 \mathrm{O}^{\text {th }}$ century, many chemical products we use are derived from petroleum. This linear use of carbon takes petrochemical feedstocks from the earth, which, after a short period of use, end up as carbon dioxide in the atmosphere. The more sustainable biobased economy has chemicals produced from renewable resources. Carbon dioxide and water are converted to sugars by plants. These can be converted to green chemicals by fermentation with bacterial cell factories. These green chemicals are used for their respective applications and if they can no longer be used, or re-used, they can be converted back to carbon dioxide forming a closed loop. The need to shift from an oil-based economy to a biobased economy is becoming more and more evident. Last year's Paris Agreement aims to combat climate change and accelerate and intensify the actions and investments needed for a sustainable low-carbon future. The Dutch government translated this in the ambition to establish a circular economy before 2050 and to reduce the use of primary raw materials, including petrol-based ones, with $50 \%$ before 2030. It defined a dedicated program to realize this (Dijksma \& Kamp, 2016). The re-use of materials is the central theme of the circular economy: waste does not exist. In addition, production of chemicals from renewable feedstocks is an integral part of this vision. The anticipated growth of the biobased economy will be largely dependent on the technological advancements in the years to come.

Before I will elaborate on what advancements I foresee for industrial strain development, I would like to spend a few words on its history. Originally, bacteria were used how they were isolated. Over the last decades, development of metabolic engineering technologies have enabled specific fine-tuning of these bacteria to optimize their productivity or, even one step further, to divert their metabolism to have them produce non-natural products.

\section{Industrial fermentation}

Industrial fermentation for production of chemicals outdates their production from petroleum. Fermentation of food products has a history of over thousands of years. Lactic acid fermentation was the first industrial fermentation process for production of a pure chemical. The French scientist Edmond Frémy reported in 1841 a process for large-scale production of lactic acid from fermentation of milk. At the time, the role of bacteria was not yet identified. It was Louis Pasteur who in 1858 described the lactic "yeast". In 1881 Charles Avery filed a United States patent on an improved process for the manufacture of lactates by fermentation using a lactic ferment. A few years later Avery opened the first industrial lactate fermentation plant in Littleton (Benninga, 1990). Around the same time Carl Wehmer discovered fermentation of 


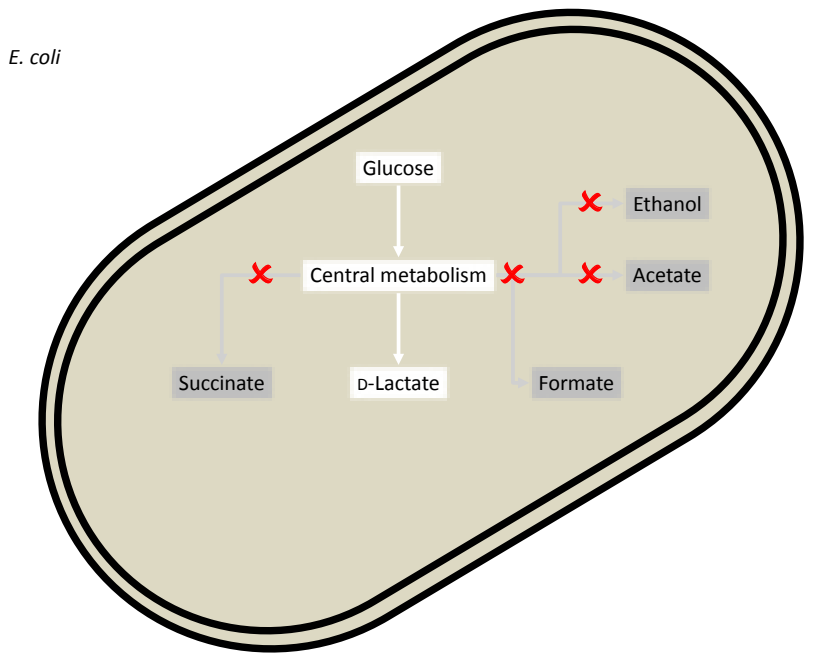

Figure 2. Metabolic engineering of E. coli for production of D-lactic acid from glucose (Zhou et al., 2006). Source E. coli electron microscopy picture:

Wadsworth.org.

citric acid by two species of fungi. He developed the industrial process that resulted in the first amounts of fermentative citric acid in the Alsace in 1893 (Benninga, 1990).

Another fermentation process with a long history is the acetone-butanol-ethanol fermentation, abbreviated ABE. This fermentation uses Clostridium acetobutylicum. The process was developed by the chemist Weizmann, who later became the first president of Israel. The production of explosives in England during World War I gave rise to a high demand for acetone as solvent. In 1916 the Weizmann process was used to start-up industrial-scale ABE fermentation (Moon et al., 2016). The years after, it became the second largest fermentation process next to ethanol. The ABE fermentation declined in the 1950 s as a result of the rapid advances in petrochemical industry. Lately, there has been renewed interest in bio-butanol production by fermentation from several industrial parties.

\section{From metabolic engineering to synthetic biology}

Advances in molecular biology tool development allowed for design and construction of industrial production strains through metabolic engineering. The best studied bacterium, Escherichia coli has been the organism of choice for many advanced engineering studies. I will give three examples of increasing level of engineering complexity to generate industrial production strains from E. coli. 


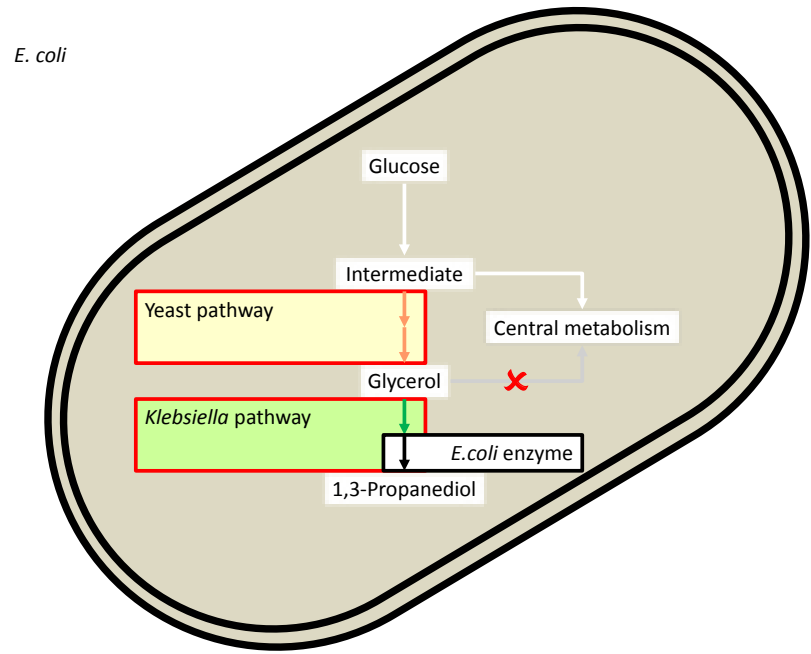

Figure 3. Metabolic engineering of E. coli for production of 1,3-propanediol from glucose (Nakamura \& Whited, 2003). Source E. coli electron microscopy picture: Wadsworth.org.

The first example is construction of a strain for production of D-lactic acid. This chemical can be used to produce chiral molecules in, for instance, the agrochemical industry. In addition, it can be polymerized to poly-lactic acid (PLA) that can be used to produce bioplastics. Natural E. coli strains will ferment sugars to a mixture of acetate, ethanol, formate, D-lactate and succinate. To obtain a production strain that only produces d-lactate, the conversion pathways to the other products need to be blocked. This can be done by removing key genes encoding those pathways from the E. coli chromosome. By doing so, researchers from the University of Florida generated an E. coli strain that only produced D-lactic acid (Zhou et al., 2006).

The second example is the construction of an industrial 1,3-propanediol production strain. 1,3-Propanediol is an oil-derived versatile chemical that can be formulated into a many industrial products such as polymers for fibers. In nature, 1,3-propanediol is produced from glycerol under anaerobic conditions by several bacteria. In industry the use of glucose or sucrose is preferred over that of glycerol. Hence, an ambitious metabolic engineering project was initiated in the 1990s by a research team from Genencor in collaboration with DuPont, at the time separate companies, to produce 1,3-propanediol from glucose with E. coli (Nakamura \& Whited, 2003). The envisioned production was from glucose via glycerol to 1,3-propanediol. As E. coli is a poor glycerol producer and has no intrinsic capacity 


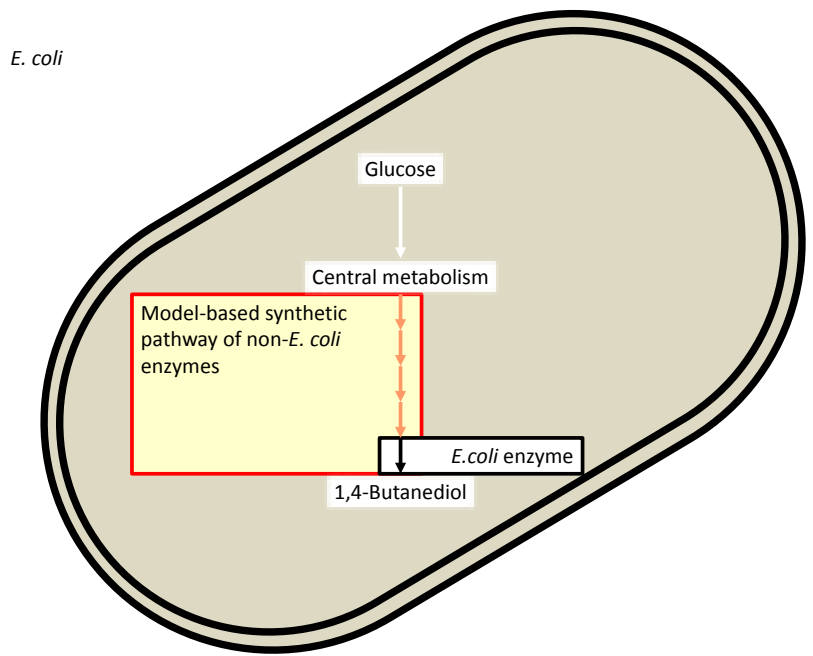

Figure 4. Metabolic engineering of E. coli for production of 1,4-butanediol from glucose (Burgard et al., 2016). Source E. coli electron microscopy picture: Wadsworth.org.

to produce 1,3-propanediol, the strain had to be provided with pathways from non-E. coli origin. The glycerol pathway was taken from baker's yeast Saccharomyces cerevisiae. The subsequent two conversion steps from glycerol to 1,3-propanediol were taken from Klebsiella pneumoniae. Surprisingly, it turned out that the second step of this conversion was best performed by an endogenous $E$. coli protein of previously unknown function and not by the K. pneumoniae enzyme. Further strain development was aimed at improving the yield of 1,3-propanediol. This was achieved by elimination of E. coli metabolic pathways competing for consumption of glycerol and optimization of glucose uptake. Together with some additional modifications, the resulting strain outperformed natural strains and is still being used by DuPont for industrial production of 1,3-propanediol.

The third example is the most complicated one. With the onset of full genome sequencing, genome-scale models became available. The accumulation of information allowed for novel combinations of genes to build synthetic pathways. Genomatica started as a software company for genome-scale models. Later, it started applying its models to design and build new production strains.

1,4 -Butanediol is a large volume oil-derived chemical with applications in plastics and fibers. No natural production pathways for its production are known. Therefore, production of 1,4-butanediol from glucose in E. coli does not only require 
combination of heterologous enzymes from different origin, but also depends on enzyme flexibility to catalyse non-natural conversions of non-native substrates and products. This could only be accomplished by an integrated approach including metabolic modelling, high-throughput pathway and strain construction, quantitative small-scale screening and systems biology (Burgard et al., 2016). The bio-butanediol pathway was designed by bioinformatics analyses of enzymes that catalyze analogous transformations. High-throughput in-vivo and in-vitro testing was used to identify the best combination. Subsequent steps were required to eliminate byproducts, improve the redox balance and increase yield. This also included exchange of the first generation of pathway enzymes by faster and more active variants. In the end these engineering cycles resulted in a strain that is currently being implemented at commercial scale (Burgard et al., 2016).

With these few examples I have illustrated how both natural bacteria and genetically modified organisms can be applied as bacterial cell factories for industrial production of green chemicals. The recent advances in metabolic engineering technologies allow diversification of product portfolio to non-natural products, broadening the potential to replace petrol-based products with green variants. Still, most of these efficient technologies are restricted to modification of a single bacterial species as production organism, E. coli, which is not necessarily the best host for all products and all processes.

\section{Feedstocks}

Now let me go back to the concept of the bacterial cell factory. Feedstocks are converted to useful products. A logical question is what feedstocks to use for the biobased economy? Today, most industrial fermentation processes use sucrose or glucose as feedstock. The choice between these mainly depends on availability of the feedstocks at the geographic location of the production facility. Sucrose is derived from sugar beets or from sugarcane. Glucose is derived from starch, which is either corn-starch or tapioca starch. Although these are efficient feedstocks, they are just a minor part of the total crop that is grown to produce them. Efficient use of the lignocellulosic biomass would add significant feedstock potential from the same agricultural area. Next to lignocellulosic biomass from food crops, there is also non-food biomass available that can be used as substrate. Examples are wood derived from forestry or energy crops such as switch grass or elephant grass. Use of feedstocks that can grow on marginal lands adds even more available feedstock and economic growth potential.

Lignocellulose is the dry-matter of plant biomass and contains the fermentable sugars stored as the sugar polymers cellulose and hemi-cellulose. Cellulose is a 
glucose polymer and hemi-cellulose is a substituted xylose polymer. Extensive pretreatment is required to obtain fermentable sugars from these polymers and potential fermentation inhibitors are generated in the process. Enzymatic conversion is often part of this pretreatment. Biorefineries are the industrial sites where biomass is converted to fermentable sugars, and subsequently to green chemicals. At the moment there are four biorefineries operational for production of bioethanol from lignocellulosic subtrates. Two in the United States from DSM-Poet and DuPont, one in Brazil from GraalBio and one in Italy from $M \& G$.

\section{The ideal bacterial cell factory}

The next question is which bacterium to use as bacterial cell factory? The ideal bacterial cell factory should have the potential to produce the target product at high productivities and yield (Gustavsson \& Lee, 2016). Its substrate flexibility preferably allows for the use of sucrose, glucose, xylose and arabinose to allow for fermentation of lignocellulosic substrates. Its nutrient requirements should allow for cost-effective cultivation in minimal medium. Tolerance against inhibitors generated in the lignocellulose pretreatment would be a pro, as would be tolerance against high product titres. Preferably, the organism should be able to grow under anaerobic or, at least, micro-aerobic conditions, but not be too sensitive to oxygen exposure. In general, the organism should be stable, robust against fluctuations in process conditions and insensitive to phage infections or microbial contamination. If the production organism does not combine all of these aspects already, or if it does not produce the target product, genetic accessibility is a prerequisite to introduce those characteristics by metabolic engineering. No organism combines all desired characteristics. The ease of engineering and the broad knowledge on its physiology has made many choose for $E$. coli. Some other bacteria have reasonable engineering possibilities, but many lack efficient tools. Further development of genetic tools for these more recalcitrant organisms would liberalize the strain development field.

\section{The strain development cycle}

Bacterial cell factories are developed using iterative cycles of design, build, test, and learn. Preferably, the production organism of choice already contains many of the desired characteristics.

\section{Design}

The traits that are missing are defined in the design phase. These can be complete new pathways that need to be added (as described for the production of 1,3-propanediol and 1,4-butanediol), elimination of pathways resulting in byproducts (as described for the production of D-lactic acid), or fine-tuning of expression levels of the bacteria's own pathway genes. Genome-scale metabolic 


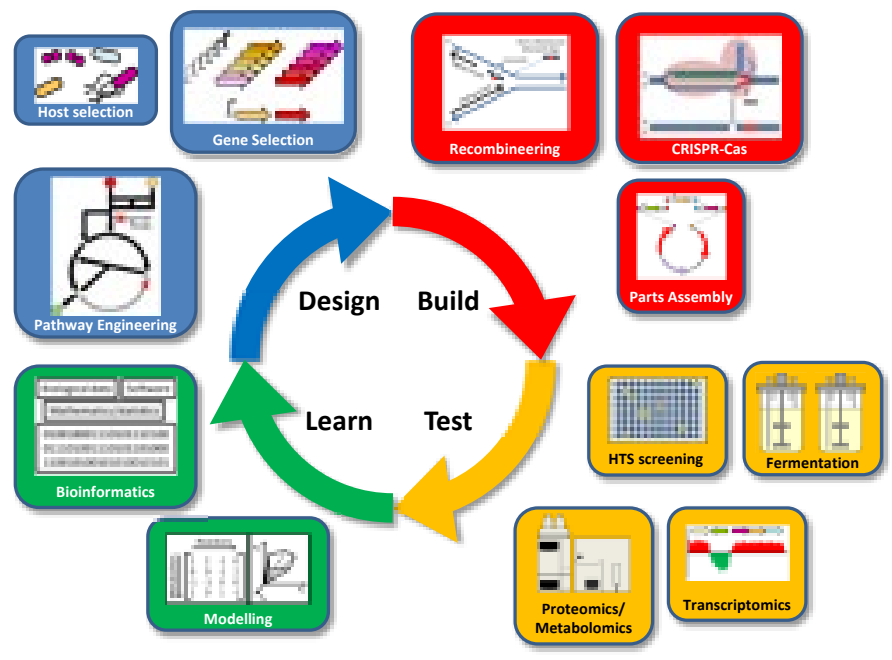

Figure 5. The design-build-test-learn cycle of strain development.

models are instrumental in this step, in particular in subsequent cycles when the most obvious modifications have been applied and optimization targets are less obvious.

\section{Build}

In the build phase the metabolic engineering is performed. The efficiency of the build phase depends on the genetic tools available. For E. coli high throughput strain engineering tools are available that allow to change many parts of the DNA in a single and relatively simple experiment. Most other bacteria lack such efficient tools, although tool development is catching up for quite a few. Two specific tools are worth mentioning for their importance in high-throughput strain construction: recombineering and CRISPR-Cas. Recombineering uses small synthetic DNA fragments to introduce the desired changes into the chromosome. These small fragments are introduced into the cells by transformation. Specific recombineering proteins, called beta or RecT, make sure that they are incorporated into the chromosome during DNA replication. More than one small DNA fragment can be introduced in parallel, a process called multiplexing, but only part of the population will obtain the modifications and these need to be selected for (Wang et al., 2009). The CRISPR-Cas technology can be used to enrich for the modified strains by cutting the chromosomes via targeting of the non-modified DNA sequences. Development of these recombineering and CRISPR-Cas tools for other bacteria will probably be crucial for efficient strain construction. 


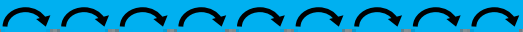

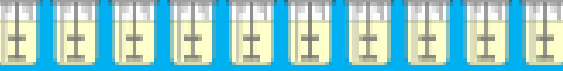 \\ Adaptive Laboratory Evolution}

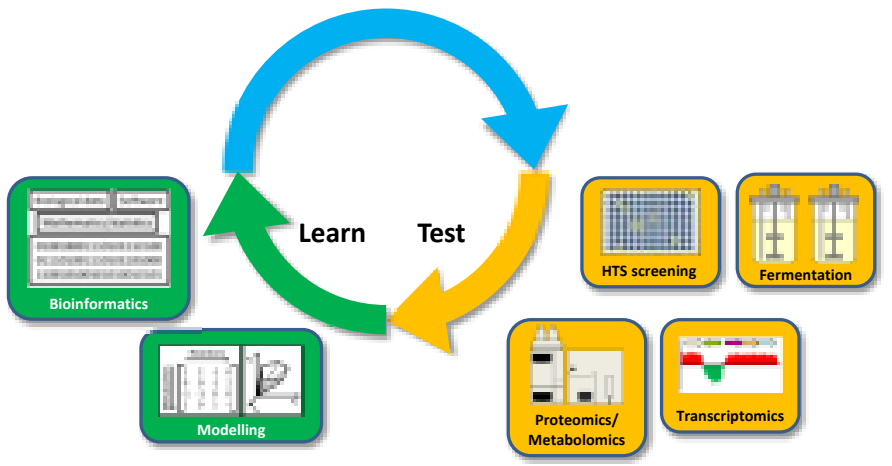

Figure 6. Adaptive laboratory evolution cycle.

\section{Test}

The performance of the strains constructed in the build phase needs to be established in fermentations in the test phase. Preferably, transcriptomics, proteomics, and metabolomics studies are performed to get a better understanding of all effects that result from the modifications, including potential unwanted side-effects. As these experiments are laborious, time-consuming, and costly, a pre-selection of mutant strains needs to be performed. Often results from simple 96-well plate assays are not sufficiently predictive to be useful. Several reporter systems have been developed that turn cells into fluorescent indicator strains for high productivity (Mahr \& Frunzke, 2016; Yang et al, 2013). Still, the examples are all for titres that are well below industrially relevant ones, and it remains to be seen if the dynamic range of these biosensor systems can be stretched to be applied to select for improved strains at those high product concentrations. It is to be expected that the advances in microfluidics and microdroplet technologies will open up new avenues of high-throughput strain selection, including advanced mass spectrometry analytics and single-cell transcriptomics (Petzold et al., 2015; Kou et al., 2016).

\section{Learn}

The fourth step in the cycle is the learn phase. This includes the bioinformatics analyses and interpretation of all data obtained in the test phase and feeding it into metabolic models to define next round's targets. 


\section{Adaptive laboratory evolution}

A complementary approach to the design and build phases is adaptive laboratory evolution. By repeated subculturing spontaneous mutations are selected for that result in improved growth. This can be used to develop increased resistance to high product concentrations or faster growth on a carbon source. The DNA sequences of the resulting strains can be compared to those of the parental strains to identify specific mutations responsible for the improved phenotype. This information can be fed back to the design phase.

So far, I have been setting the scene of the research field and illustrated several aspects relevant to developing bacterial cell factories. The last part of my lecture I will elaborate on my own work and plans for the near future.

\section{Beyond E. coli}

In my research I will focus on bacterial production of green chemicals, in particular of organic acids. These can be applied as purified products, like lactic acid or succinic acid, or can be converted into chemical derivatives including biopolymers, like poly-lactic acid. When trying to establish fermentations on lignocellulosic substrates, it seems logical to choose bacteria that naturally grow on plant waste. Thermophilic Gram-positives are such bacteria. This group of relatively unexplored thermophiles has many relevant characteristics that make them attractive as production organism for green chemicals. They produce various organic acids, have the ability to ferment a broad range of carbon sources and are suited for fermentation of lignocellulosederived substrates. Moreover, their thermophilic nature makes them particularly attractive for industrial processes by increased reaction rates, limited cooling costs and cooling times, and improved simultaneous saccharification and fermentation capacities. In the biorefinery concept first pretreatment steps are typically performed at temperatures well above $100^{\circ} \mathrm{C}$. Subsequently, the fermentable sugars are released in the step called liquefaction or saccharification, which is performed at temperatures around 50 to $55^{\circ} \mathrm{C}$. When using E. coli, the fermentor needs to be cooled down to
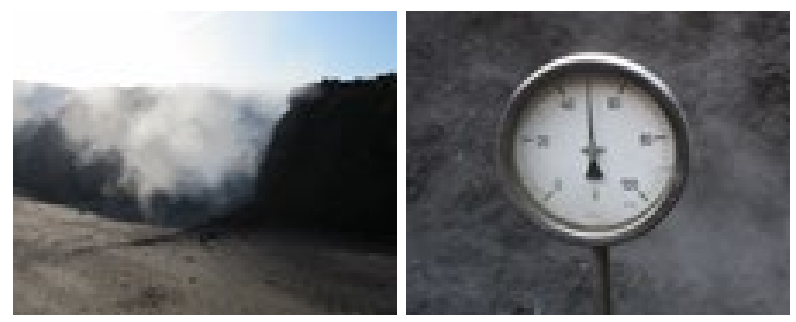

Figure 7. Compost as a source for thermophilic bacilli. 


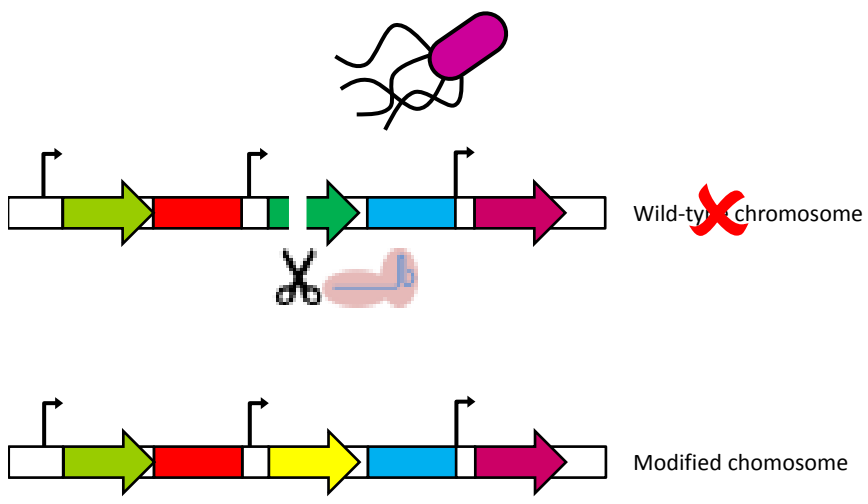

Figure 8. Use of Cas9 as counterselection tool to target and eliminate wild-type sequences.

$37^{\circ} \mathrm{C}$, which requires energy and time. The use of a thermophile would eliminate such cooling step and also allow for simultaneous saccharification and fermentation, adding all to a more economic process. Therefore, my first research focus lies on isolating the right thermophiles and developing the genetic tools that allow for efficient metabolic engineering. That way all desired and complex characteristics, such as the thermophilic nature and the ability to make optimal use of lignocellulosic sugars, which cannot be easily transferred to E. coli, can be exploited and complemented with optimized organic acids production pathways.

My group is positioned in the Bacterial Genetics group at the Laboratory of Microbiology. The first studies in our lab were dedicated to isolating strains that make optimal use of plant sugars. For this, we looked at compost as isolation source. In compost plant biomass is partially decomposed by the activity of a complex microbial community. Therefore, compost is an ideal source for bacteria that are specialized in biomass degradation. Our first focus was on thermophiles that were able to use the main sugars that can be obtained from lignocellulosics. These are glucose from cellulose and xylose from hemicellulose. Elleke Bosma and Tom van de Weijer isolated a Bacillus smithii strain that was genetically accessible, could use xylose and glucose simultaneously, and produced lactic acid (Bosma et al., 2015a). Tools were developed to eliminate genes, which were applied for the construction of multiple knockouts (Bosma et al., 2015b).

Having laid the fundaments for genetic engineering, we continued to improve our toolkit. Ioannis Mougiakos and Elleke Bosma have recently developed a method to apply Casy from Streptococcus pyogenes for genome editing of thermophiles 
(Mougiakos et al., 2017). As explained before, Cas9 can be used to simplify enrichment of mutants, as it can be applied to target and eliminate wild-type sequences. This drastically improves accuracy and speeds-up generation modified strains. Our approach makes use of the thermophilic nature of B. smithii, with optimal growth at $55^{\circ} \mathrm{C}$, where Casg is inactive and recombination can take place, and its ability to grow at $37^{\circ} \mathrm{C}$, where Cas9 will eliminate the unwanted wild-type cells. This trick turned out to be very successful. Having sufficient efficiency in the build phase, we now shift towards the next steps of the strain development cycle, while keeping an eye on continuous improvement.

Preferably, production strains would be able to directly use the hemicellulose and cellulose fractions of lignocellulose. Such strains would need only limited pretreatment of the biomass. In the biorefinery fermentable sugars are generated in a liquefaction step, in which enzymes are used to break-down the sugar polymers. Bacteria possessing hemicellulase or cellulase activity would not require such a step, or could do with less added enzymes, making the process more economic. Tijn Daas isolated thermophilic bacilli from compost that can consume the hemicellulose part of lignocellulose. He selected a genetically accessible Geobacillus thermodenitrificans strain that can make lactate from xylan (Daas et al., 2016). He also managed to introduce different type of cellulases, exo-glucanases and endoglucanases, into this strain. With this work he made the important first steps in developing an economic fermentation process from lignocellulosic substrates.

Succinate is an organic acid with great potential for production of biomaterials. Several microbial succinate production strains have been developed, some of which are being commercialized (Ahn et al., 2016). So far, no thermophilic production strains have been developed. Recently, two projects have been initiated in which Joyshree Ganguly and Jeroen Koendjbiharie try to set-up the strain development infrastructure to produce organic acids with anaerobic thermophilic clostridia. The species selected for this project is the only thermophile producing succinate as its main fermentation product. Although clostridia are known as notorious recalcitrant to genetic engineering and difficult to handle, the advanced tools developed in the other projects are expected to expedite successful engineering protocols. This would be a very important step forward in broadening the number of strains available for industrial strain development.

\section{Future directions}

These are exciting times for biotechnologists. Advanced genetic engineering tools like recombineering and CRISPR-Cas are being developed for many organisms.

Developments in robotics and automation allow high-throughput strain construction 
in laboratories called biofoundries. At the same time microfluidic developments allow for miniaturization. Complete strain development processes can be combined on a single chip and whole laboratories are reduced to bench-top machines (Gach et al., 2016). Where E. coli used to be the common work-horse as bacterial cell factory, tool development for others is improving fast and the field is liberalizing. It cannot be expected that $E$. coli will be the one-size-fits-all solution to industrial fermentation. Several challenges still lie ahead of us. With high-throughput metabolic engineering tools quickly maturing, the screening phase will become limiting. Moreover, a better understanding of physiology and the function of hypothetical genes is still high on the agenda for many organisms. In particular, to improve the predictive power of metabolic models. A better insight in enzyme flexibility will also add to this. Adaptive laboratory evolution will be instrumental in developing growth-coupled complex traits. In addition, it will provide valuable information on the underlying mutations involved in the phenotypes. Through development of efficient designbuild-test-learn cycles for non-model organisms, such as thermophilic Grampositives, I intend to contribute to the field and, ultimately, contribute to a smooth transition to the biobased economy.

\section{Academic embedding and education}

The university is a place for fundamental research and education. The strain development cycle required for successful development of bacterial cell factories involves many different disciplines that each have their specialization. As it would be impossible to master all aspects within one research group, collaborations between different groups within Wageningen University and Research and between our university and other universities and industries are essential. Current work already involves collaborations with colleagues from the chair groups Food Chemistry, Food Microbiology, and Systems and Synthetic Biology, while new collaborations will be initiated. National and international collaborations with other universities have been established and will be extended. For me the link with industry is a natural one and all projects have industrial support.

The Wageningen University mission is to explore the potential of nature to improve the quality of life. This results in a strong focus on the biobased economy. Development of the biobased economy strongly depends on interactions between academia and industry. My position as special professor allows me to perform fundamental research at Wageningen University and translate the knowledge to the industrial practise. Next to that I am in a position where I can translate questions from industrial practise back to fundamental research questions that are relevant for the sector as a whole. Through my educational activities I can explain students about the importance of interactions between academia and industries. In collaboration 
with colleagues from Microbiology, Biobased Chemistry and Technology and Bioprocess Engineering we are setting up a new course Advanced Biobased Conversion as part of the MicroMasters program Biobased Sciences for Sustainability and the master Biobased Sciences. In the master course Applied and Molecular Microbiology I teach the new generation of biotechnologists both the basics of and the latest developments in genome editing. To this end, the course is updated on a yearly basis. It is very rewarding to see that several taltented students continued with their master thesis in my group or decided to do an internship at Corbion.

\section{Concluding remarks}

I am coming to the end of this lecture. I have explained the relevance of bacterial cell factories in the biobased economy. Biobased feedstocks can be converted to green chemicals that can be used to produce materials such as bioplastics. Thermophiles have many advantages for application in biorefineries. Advances in efficient metabolic engineering and other tools are required to allow optimal execution of design-build-test-learn cycles of strain development. Adaptive laboratory evolution can be an attractive alternative for specific growth-coupled optimization processes. Through my research projects and teaching activities I aim to contribute to a transition from an petrol-based economy to a biobased economy.

\section{Words of gratitude}

My final words will be my words of gratitude. I would not have been able to get to this privileged position, without the support of many.

First of all, I would like to thank my parents for giving me the freedom to do the things I wanted to do and to give their unconditional support. My mother passed away in 1996 in the middle of my PhD period. My father passed away at end of 2015, just before I got appointed. He was very involved with the process and would have been very proud to be here.

I would like to thank the former rector Martin Kropff and the current rector Arthur Mol for their confidence in me. Also thanks to Raoul Bino for his support to my appointment.

Special thanks goes to my mentor Willem de Vos. I admire your energy, speed of thinking (and talking), expertise, scientific leadership and managerial skills. We got to know each other when I did my master thesis at the Bacterial Genetics Group in the Laboratory of Microbiology in 1991. You became my promotor for the PhD project that I performed in your group at NIZO food research. And you seem to be involved in every major step I took afterwards. After eight years at NIZO, you alerted me on a position at Purac, now Corbion. This gave me the possibility to start-up my own strain development 
group. And you were crucial in getting this Special Professorship organized.

My time at NIZO was a very important one. The cellar was a cauldron of fun and science. It is amazing to see how many of my former direct colleagues made it to professor.

The process of becoming a special professor takes time. All the time, it was supported by my superiors from Purac and, later, Corbion. Therefore, I would like to thank Peter Jansen, Jan van Breugel, Rop Zoetemeyer, Tony Else, Heleen Goorissen, Sven Thormählen, Tjerk de Ruiter, and Marcel Wubbolts for their continuous support.

I would like to thank all my Corbion colleagues, particularly from the R\&D Biotechnology department. I specifically want to mention my Strain Development team, who made an important contribution to my professional success. Here, I should mention Mariska van Hartskamp, who has a hand in nearly everything I do at Corbion. And even a hand in this lecture.

I have been a visiting scientist at the Laboratory of Microbiology from 2009 onwards. I would like to thank everyone for hosting me. It is a pleasure to see that we now have become real colleagues. Special thanks to the people from the Bacterial Genetics Group, and in particular John van der Oost. Being in close proximity to one of the godfathers of CRISPR-Cas research turned out to be very fruitful.

Needless to say that I want to thank the current and past Bacterial Cell Factories team. Elleke Bosma, Tom van de Weijer, Tijn Daas, Ioannis Mougiakos, Jeroen Koendjbiharie, Joyshree Ganguly and their students are the driving forces, hands and brains that make everything happen.

Ik wil mijn familie en vrienden bedanken voor hun steun en interesse.

Suzan, het is een genot om je te zien opgroeien. We lijken zeer op elkaar. Toch kan je me vaak een spiegel voorhouden en op jouw manier zaken relativeren.

Marja. Waar zou ik zonder jou zijn? Bedankt dat je er voor me bent. Bedankt voor je liefde, zorg en steun voor al meer dan 26 jaar. Ik hoop dat we daar nog vele jaren aan toe mogen voegen.

Dear audience. Thank you for coming to Wageningen to attend this lecture.

Ik heb gezegd 


\section{References}

Ahn, J.H., Jang, Y.S., Lee, S.Y. 2016. Production of succinic acid by metabolically engineered microorganisms. Curr. Opin. Biotechnol. 42:54-66.

Benninga, H. 1990. A history of lactic acid making. Kluwer Academic Publishers. Dordrecht.

Bosma, E.F., van de Weijer, A.H.P., Daas, M.J.A., van der Oost, J., de Vos, W.M., van Kranenburg, R. 2015a. Isolation and screening of thermophilic bacilli from compost for electrotransformation and fermentation: characterization of Bacillus smithii ET 138 as a new biocatalyst. Appl. Environ. Microbiol. 81:1874-1883.

Bosma, E.F., van de Weijer, A.H.P., van der Vlist, L., de Vos, W.M., van der Oost, J., van Kranenburg, R. 2015b. Establishment of a markerless gene deletion tools in thermophilic Bacillus smithii and construction of multiple mutant strains. Microb. Cell Fact. 14:99.

Burgard, A., Burk, M.J., Osterhout, R., Van Dien, S., Yim, H. 2016. Development of a commercial scale process for production of 1,4-butanediol from sugar. Curr. Opin. Biotechnol. 42:118-125.

Daas, M.J.A., van de Weijer, A.H.P., de Vos, W.M., van der Oost, J., van Kranenburg, R. 2016. Isolation of a genetically accessible thermophilic xylan degrading bacterium from compost. Biotechnol. Biofuels 9:210.

Dijksma, S.A.M., Kamp, H.G.J. 2016. Nederland circulair in 2050. Rijksbreed programma Circulaire Economie. Ministerie van Infrastructuur en Milieu en het ministerie van Economische Zaken.

Gach, P.C., Shih, S.C.C., Sustarich, J., Keasling, J.D., Hillson, N.J., Adams, P.D., Singh, A.K. 2016. A droplet microfluidic platform for automating genetic engineering. ACS Synth. Biol. 5:426-433.

Gustavsson, M., Lee, S.Y. 2016. Prospects of microbial cell factories developed through systems metabolic engineering. Microb. Biotechnol. 9:610-617.

Kou, S., Cheng, D., Sun, F., Hsing, I.M. 2016. Microfluidics and microbial engineering. Lab Chip 16:432-446. 
Mahr, R., Frunzke, J. 2016. Transcription factor-based biosensors in biotechnology: current state and future prospects. Appl. Microbiol. Biotechnol. 100:79-90.

Moon, H.G., Jang, Y.S., Cho, C., Lee, J., Binkley, R., Lee, S.Y. 2016. One hundred years of clostridial butanol fermentation. FEMS Microbiol. Lett. 363: fnwoo1.

Mougiakos, I., Bosma, E.F., Weenink, K., Vossen, E., Goijvaerts, K., van der Oost, J., van Kranenburg, R. 2017. Efficient genome editing of a facultative thermophile using mesophilic spCas9. ACS Synth. Biol. DOI: 10.102/acssynbio.6boo339.

Nakamura, C.E., Whited, G.M. 2003. Metabolic engineering for the microbial production of 1,3-propanediol. Curr. Opin. Biotechnol. 14:454-459.

Petzold, C.J., Chan, L.J., Nhan, M., Adams, P.D. 2015. Analytics for metabolic engineering. Front. Bioeng. Biotechnol. 3:135.

Wang, H.H., Isaacs, F.J, Carr, P.A., Sun, Z.Z., Xu, G., Forest, C.R., Church, G.M. 2009. Programming cells by multiplex genome engineering and accelerated evolution. Nature 460:894-898.

Yang, J., Seo, S.W., Jang, S., Shin, S.I., Lim, C.H., Roh, T.Y., Jung, G.Y. 2013. Synthetic RNA devices to expedite the evolution of metabolite-producing microbes. Nature Commun. 4:1413.

Zhou, S., Shanmugam, K.T., Yomano, L.P., Grabar, T.B., Ingram, L.O. 2006. Fermentation of $12 \%(\mathrm{w} / \mathrm{v})$ glucose to $1.2 \mathrm{M}$ lactate by Escherichia coli strain SZ194 using mineral salts medium. Biotechnol. Lett. 28:663-670 


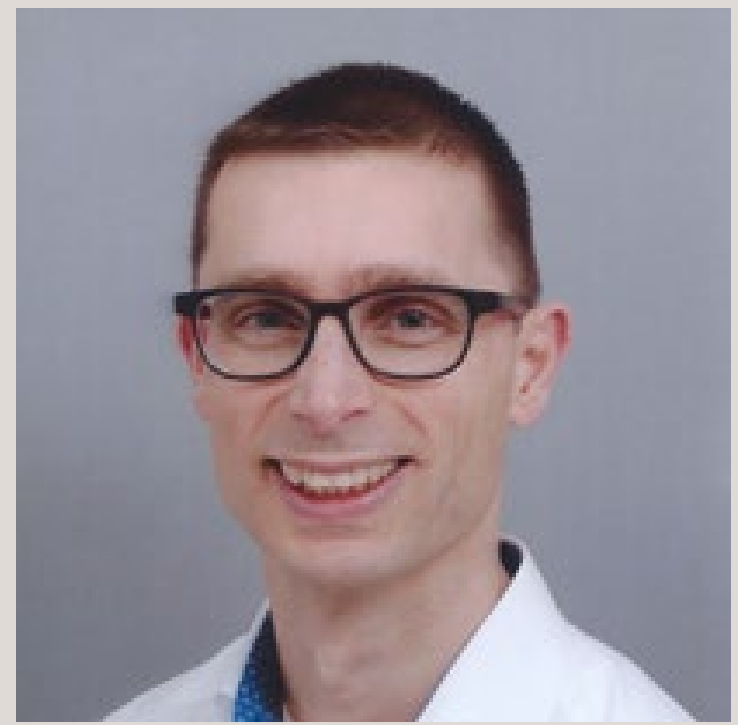

Prof.dr Richard van Kranenburg

'The research of Bacterial Cell Factories aims to apply bacteria for production of biobased chemicals from renewable resources. The focus lies on thermophilic Gram-positives. This group of relatively unexplored thermophiles has many relevant characteristics that make them attractive as production organism for green chemicals. Development of genetic tools is a requirement for high-throughput engineering. The scientific challenge lies in exploring and exploiting the microbial physiology of the selected production organisms, involving an integrated approach of various disciplines. Successful development of such Bacterial Cell Factories is crucial for establishing the biobased economy.' 